\title{
A NEW WAY OF THINKING ABOUT THE CURRENT ACCOUNT
}

\author{
BY ERIC O'N. FISHER ${ }^{1}$
}

Extending the theory of generational accounts, I show that the conventional current account is not related to the real effects of a country's fiscal policy. For any international array of fiscal policies, a country can implement its own policy so that the conventional government and current account deficits are zero in every period. I argue that economists should develop a new measure of the current account. This measure is forward looking and keeps track of expected transfers between countries.

\section{INTRODUCTION}

This paper uses a technique first developed by Auerbach and Kotlikoff (1987) and then generalized by Kelly (1991) to show that a country can implement its fiscal policy in a way that satisfies any exogenously imposed constraint on the path of the current account. Using the model of overlapping generations, Kelly establishes a quite general result: taxes can always be timed so that an economy's budget deficit satisfies an arbitrary constraint even though fiscal policy has real effects for every agent in every period. ${ }^{2}$ I extend this work in two directions: first by demonstrating that this intuition is true for the open economy; and second by showing that it carries naturally into stochastic environments.

Although this paper has a theoretical focus, its implications for empirical economists and policy makers are profound. The result below is not a theoretical curiosum; it gets at the essence of what economists ought to measure when they compile current account statistics. Just as a conventional corporate balance sheet is misleading if unfunded liabilities are not reported, the conventional current account is misleading when expected net transfers to abroad have changed. For example, when the United States shut down Subic Bay Naval Base and Clark Air Base in the Philippines in the months after the eruption of Mount Pinatubo, there was a change in the stream of expected net transfers to abroad. A conservative estimate of the

\footnotetext{
${ }^{1}$ I thank two anonymous referees for very helpful comments and Karl Shell for conversations that shaped profoundly my ideas on this subject. I am also grateful to Alan Viard, Jim Peck, Mario Crucini, and seminar participants at the State University of New York at Albany, Syracuse University, the Ohio State University, the 1994 summer meetings of the Econometric Society at Québec, the Australian National University, La Trobe University, Auckland University, the New Zealand Treasury, and Otago University for comments on earlier drafts of this paper. Any remaining errors are my own.

${ }^{2}$ In a simple model, McCandless with Wallace (1991, p. 88) showed that allocations in an equilibrium with government bonds can also be supported in an equilibrium with lump-sum taxes and transfers in which the government debt is zero in each period.
} 
present value of this change is 20 billion dollars. This is an increase in the United States' net foreign assets, and it should be reflected in the properly defined current account for $1992 .^{3}$

Dewald and Ulan (1990) have made a similar point. They argue that the conventional measure of the current account is misleading largely because it uses historical, not market, values of net foreign assets. I extend this insight by emphasizing that a correct measure of changes in net foreign assets ought to incorporate all foreseeable net transfers to abroad. It is likely that the market value of net foreign assets reflects accurately expected future private payments to abroad. But there is no conventional measure that captures expected unilateral public transfers to abroad. ${ }^{4}$

One implication of my work is that "balance-of-payments disequilibria" need not be related to a country's government deficit as usually measured. Hence, it may not be meaningful to make international lending conditional upon "structural adjustments" that decrease conventional measures of aggregate demand. ${ }^{5}$ Such recommendations may be misguided, and policy makers ought to use generational accounts to measure the effects of fiscal policy. On this point, Auerbach, Gokhale, and Kotlikoff (1991) are quite right.

Of course, a country's external deficit is the sum of its private and public net borrowing. This tautology is often used to argue that the external deficit places some constraints on fiscal policy. Howard (1989) gives the conventional wisdom: he describes policies that reduce a country's loss of net foreign assets when the expected profile of the trade balance may not be "sustainable." A sustainable profile for a country's external deficit depends, however, upon the fiscal policies of all the countries in the world economy, as I have emphasized elsewhere (1990). Since there is no simple relationship between the conventional government deficit and the real effects of fiscal policy, a deterioration on the conventional current account may not necessitate a decrease in the conventional government deficit.

The right way of thinking about the relationship between the internal and external deficits is to use generational accounts. In the open economy, what matters is a measure of the present value of net transfers from abroad. Again, this measure depends upon the fiscal policies of all countries in the world economy, and it need not be zero in any period. In the penultimate section of this paper, I argue that the aggregate generational current account, the annual change in the expected present value of net transfers from abroad, is an appropriate measure of the external deficit.

\footnotetext{
${ }^{3}$ The statistical discrepancy in the United States' current account deficit was roughly 12 billion in that year.

${ }^{4}$ For example, increased expected military aid from abroad in the wake of the Gulf War should be reflected as an Egyptian "foreign asset" on a meaningful measure of the external account for Egypt in 1991.

${ }^{5}$ The idea that there is a link between the conventionally measured government deficit and the external deficit is tenacious in the minds of policy makers. Williamson (1983), for example, describes the International Monetary Fund's perception of how its policies influence countries' external deficits and public sector borrowing requirements.
} 
If the aggregate generational current account worsens, then some domestic resident will suffer lower utility. This simple fact is not true of the conventional current account.

The rest of this paper is structured as follows. Section 2 describes the model and its equilibrium. Section 3 shows that the conventional current account is not meaningful. A meaningful alternative is proposed in Section 4: the aggregate generational current account. Section 5 is a brief conclusion emphasizing some of the practical implications of my arguments and putting forth an agenda for empirical work.

\section{THE MODEL AND ITS EQUILIBRIUM}

The model extends the seminal work of Balasko and Shell (1980 and 1981) by allowing for several agents in each generation and several different assets, ${ }^{6}$ and it incorporates uncertainty by adopting the framework of Manuelli and Peck (1990). In order to keep the theoretical exposition succinct, the model is presented in a very cursory manner.

The set of agents born at time $t$ is $G_{t}$, and the index set of the agents in the world economy is $G=\cup_{s=0}^{\infty} G_{s}$. Agents live for two periods; $;^{7}$ thus, the set of agents trading at time $t \geq 1$ is $G_{t-1} \cup G_{t}$. A list of countries is a partition of $G$; there are $m$ different countries. Hence, if $\mathscr{G}=\left\{G^{1}, \ldots, G^{m}\right\}$ is a partition of $G$, then $h \in G^{j} \cap$ $G_{t}$ is a resident of country $j$ born at time $t$.

I consider a stochastic exchange economy with $\ell$ perishable goods available in each period. The endowments of agent $h \in G_{t}$ are

$$
\omega_{h}=\left(0, \ldots, 0, \omega_{h}^{t}, \omega_{h}^{t+1}, 0, \ldots\right),
$$

where $\omega_{h}^{t} \in \mathbb{R}_{+}^{\ell}$ is the vector of goods the agent has at his disposal at time $t .^{8} \mathrm{I}$ make no assumptions about the location of $\omega_{h}^{t, i}$, the $i$ th good available to agent $h$ in period $t$; hence, an agent can be endowed with nontraded goods and traded goods located in other countries.

The state of the economy at time $t$ is

$$
s_{t}=\left(\left(\omega_{h}^{t}\right)_{h \in G}, \theta_{t}\right),
$$

where $\theta_{t}$ includes random variables other than the agents' endowments. I assume

\footnotetext{
${ }^{6}$ These assets are stores of value that bear state-contingent interest, and they are used to implement countries' fiscal policies. The reader should think of them as government bonds denominated in different currencies.

${ }^{7}$ This assumption is not at all restrictive; see Balasko, Cass, and Shell (1980) for an algorithm that converts any truly dynamic economy with arbitrary demographics into the one described here.

${ }^{8}$ Note that agent $h \in G_{0}$ is endowed with goods only during the (first and) last period of his life. Also, the assumption that an agent may not be endowed with positive amounts of each good is more general that that in Balasko and Shell (1980 and 1981) because I assume the existence of an equilibrium in the discussion below.
} 
that $s_{t} \in S$, a compact state space. For most of what follows, one can take $\theta_{t}$ to be constant, but I include it to allow the possibility of extrinsic uncertainty. Following Manuelli and Peck, I assume that $\left\{s_{t}\right\}_{t=1}^{\infty}$ is a Markov process with transition probability $P(s, A)$, describing the probability that $s_{t+1} \in A \subseteq S$, given that $s_{t}=s \in S$. I assume that this stochastic process has a unique invariant measure $\lambda$.

A history at time $t$ is a list of realizations of this process,

$$
s^{t}=\left(s_{1}, \ldots, s_{t}\right) .
$$

The agents in period $t$ know this history before they make their consumption and asset choices, and the description of goods and asset prices are sequences of random variables.

Agent $h \in G_{t}$ has preferences that are represented by an expected utility function defined on the goods that are available to him in the different histories that he might face. His expected utility is summarized by $E\left\{u_{h}\left(x_{h}^{t}\left(s^{t}\right)\right.\right.$, $\left.\left.x_{h}^{t+1}\left(s_{t+1}\right)\right)\right\}$, where expectations are taken with respect to the history $s^{t}$. Hence each agent's state-contingent allocation is a sequence of (measurable) functions

$$
x_{h}=\left(0, \ldots, 0, x_{h}^{t}\left(s^{t}\right), x_{h}^{t+1}\left(s_{t+1}\right), 0, \ldots\right),
$$

where both $x_{h}^{t}\left(s^{t}\right) \in \mathbb{R}_{+}^{\ell}$ and $x_{h}^{t+1}\left(s_{t+1}\right) \in \mathbb{R}_{+}^{\ell}$. The list of goods prices in the world economy is an analogous sequence,

$$
p=\left(p^{1}\left(s^{1}\right), p^{2}\left(s^{2}\right), \ldots\right)
$$

where $p^{t}\left(s^{t}\right) \in \mathbb{R}_{+}^{\ell}$. This notation emphasizes that prices depend upon the history of the world economy. I use the normalization that $p^{1,1}\left(s^{1}\right) \equiv 1$ for all histories $s^{1}$. Hence, these functions are state-contingent present value prices, and $p^{t, i}\left(s^{t}\right) / p^{t+1, i}\left(s_{t+1}\right)$ is the $i$ th commodity's realized "own-rate of interest" between periods $t$ and $t+1$.

Agents receive lump-sum tax transfers in the $m$ different fiat assets in the world economy. The vector of transfers to $h \in G_{t}$ is

$$
m_{h}=\left(0, \ldots, 0, m_{h}^{t}\left(s^{t}\right), m_{h}^{t+1}\left(s_{t+1}\right), 0, \ldots\right)
$$

where now both $m_{h}^{t}\left(s^{t}\right) \in \mathbb{R}^{m}$ and $m_{h}^{t+1}\left(s_{t+1}\right) \in \mathbb{R}^{m}$. If $m_{h}^{t, j}\left(s^{t}\right)<0$, then agent $h$ is taxed in currency $j$ after history $s^{t}$. Likewise, an agent receives a subsidy from country $j$ after history $s^{t}$ if $m_{h}^{t, j}\left(s^{t}\right)>0$.

The sequence of asset demands of $h \in G_{t}$ is

$$
y_{h}=\left(0, \ldots, 0, y_{h}^{t}\left(s^{t}\right), y_{h}^{t+1}\left(s_{t+1}\right), 0, \ldots\right),
$$

where again $y_{h}^{t}\left(s^{t}\right) \in \mathbb{R}^{m}$ and $y_{h}^{t+1}\left(s_{t+1}\right) \in \mathbb{R}^{m}$. If $y_{h}^{t, j}\left(s^{t}\right)-m_{h}^{t, j}\left(s^{t}\right)>0$, then agent 
$h \in G_{t}$ acquires net additions of (saves) type $j$ assets in the first period of his life. The present prices of the $m$ assets are

$$
q=\left(q^{1}\left(s^{1}\right), q^{2}\left(s^{2}\right), \ldots\right)
$$

where $q^{t}\left(s^{t}\right) \in \mathbb{R}_{+}^{m}$ is the vector of fiat assets prices after history $s^{t}$.

Since agents in the same generation make choices under uncertainty, there will be a market for state-contingent contracts in each period. I assume that such a market opens after these agents are born and offers a security paying a constant income in each state in the next period. The demand of $h \in G_{t}$ for this Arrow security is

$$
z_{h}=\left(0, \ldots, 0, z_{h}^{t}\left(s^{t}\right), z_{h}^{t+1}\left(s_{t+1}\right), 0, \ldots\right)
$$

where $z_{h}^{t}\left(s^{t}\right) \in \mathbb{R}$. The sequence of prices of this security is

$$
r=\left(r^{1}\left(s^{1}\right), r^{2}\left(s^{2}\right), \ldots\right)
$$

where $r^{t+1}\left(s_{t+1}\right)=r^{t+1}$ for all realizations $s_{t+1}$.

I can now state the consumer's problem succinctly. Given history $s^{t}$, agent $h \in G_{t}$ chooses $x_{h}^{t}\left(s^{t}\right), y_{h}^{t}\left(s^{t}\right)$, and $z_{h}^{t}\left(s^{t}\right)$ and also chooses $x_{h}^{t+1}\left(s_{t+1}\right), y_{h}^{t+1}\left(s_{t+1}\right)$, and $z_{h}^{t+1}\left(s_{t+1}\right)$ for each $s_{t+1}$ to solve ${ }^{9}$

$$
\text { maximize } E\left\{u_{h}\left(x_{h}^{t}\left(s^{t}\right), x_{h}^{t+1}\left(s_{t+1}\right)\right)\right\}
$$

subject to

(i) $p \cdot x_{h}+q \cdot y_{h}+r \cdot z_{h} \leq p \cdot \omega_{h}+q \cdot m_{h}$;

(ii) $x_{h}^{t}\left(s^{t}\right) \geq 0, x_{h}^{t+1}\left(s_{t+1}\right) \geq 0$;

(iii) $y_{h}^{t}\left(s^{t}\right)+y_{h}^{t+1}\left(s_{t+1}\right) \geq 0$; and

(iv) $z_{h}^{t}\left(s^{t}\right)+z_{h}^{t+1}\left(s_{t+1}\right) \geq 0$.

In other words, he maximizes expected utility conditional on the history $s^{t}$. Note that these constraints hold for every realization $s_{t+1}$; hence, (i) expresses compactly as many constraints as there are states of nature in period $t+1$. Constraint (i) states that the consumer maximizes expected utility subject to a present-value budget constraint, and its inner products are well defined because only finitely many of the elements of $x_{h}, y_{h}, z_{h}, \omega_{h}$, and $m_{h}$ are not zero. Constraint (ii) states that agents may not short any commodity, and (iii) states that no agent may die a net debtor in any of the $m$ currencies. It is important to emphasize that (iii) allows an agent to borrow and lend in any currency in order to smooth consumption during the course of his life. Finally, constraint (iv) states that the agent may not create an Arrow security that he does not redeem.

\footnotetext{
${ }^{9}$ The problem for $h \in G_{0}$ is quite simple since he faces no uncertainty.
} 
Let $Y_{h}$ describe the cumulative fiat asset holdings of agent $h \in G_{t}$. This sequence is given explicitly by

$$
Y_{h}=\left(0, \ldots, 0, y_{h}^{t}\left(s^{t}\right), y_{h}^{t}\left(s^{t}\right)+y_{h}^{t+1}\left(s_{t+1}\right), 0, \ldots\right),
$$

each of whose elements is in $\mathbb{R}^{m}$. Consider also

$$
M^{t}\left(s^{t}\right)=\sum_{k=1}^{t} \sum_{h \in G} m_{h}^{k}\left(s^{k}\right),
$$

the $m$-dimensional vector representing the sum of all injections of the different currencies that have occurred up to time $t$. Then

$$
M=\left(M^{1}\left(s^{1}\right), M^{2}\left(s^{2}\right), \ldots\right)
$$

is a profile of national debts for all $m$ countries. Also, let

$$
Z_{h}=\left(0, \ldots, 0, z_{h}^{t}\left(s^{t}\right), z_{h}^{t}\left(s^{t}\right)+z_{h}^{t+1}\left(s_{t+1}\right), 0, \ldots\right)
$$

be this agent's stock of the Arrow security.

A rational expectations equilibrium is a sequence of goods and asset prices and a corresponding list of allocations and asset demands that are all functions of the history of the economy. Thus, for history $s^{t}$ and realization $s_{t+1}$, a rational expectations equilibrium consists of

$$
\left\{\left(p^{t}\left(s^{t}\right), q^{t}\left(s^{t}\right), r^{t}\left(s^{t}\right)\right)\right\}_{t=1}^{\infty} \quad \text { and } \quad\left\{\left(x_{h}, y_{h}, z_{h}\right)\right\}_{h \in G}
$$

such that

(i) $\left(x_{h}, y_{h}, z_{h}\right)$ solves (1);

(ii) $\sum_{h \in G} x_{h} \leq \sum_{h \in G} \omega_{h}$;

(iii) $\sum_{h \in G} Y_{h} \leq M$; and

(iv) $\sum_{h \in G} Z_{h} \leq 0 .{ }^{10}$

Condition (i) states that allocations and asset demands are chosen to maximize each agent's expected utility subject to the natural constraint after any history. Condition (ii) is that of material balances; ${ }^{11}$ it is an infinite-dimensional vector inequality each of whose elements keeps track of one dated commodity. This inequality is well defined because there are only finitely many agents in the world economy at any one time. Condition (iii) shows how the stocks of the $m$ different asset markets clear; it

\footnotetext{
${ }^{10}$ I stipulate that $y_{h}^{0}=0 \in \mathbb{R}^{m}$ and $z_{h}^{0}=0$ for all $h \in G_{0}$.

${ }^{11}$ If there are nontraded goods in the $m$ different countries, then (ii) is necessary but not sufficient. One must further stipulate that the demands and supplies for such goods involve only subsets of the agents. Then the extra condition is $\sum_{h \in G^{j}} x_{h}^{t, i}\left(s^{t}\right) \leq \sum_{h \in G^{j}} \omega_{h}^{t, i}\left(s^{t}\right)$ for each commodity $(t, i)$ that is a nontraded good in country $j$ after history $s^{t}$.
} 
too is an infinite-dimensional vector inequality. The right side of (iii) describes the evolution of the stock of $m$ different outside assets; hence (iii) is the analog of (ii), although one condition expresses an equilibrium in stocks of assets and the other an equilibrium in the flow of commodities. Constraint (iv) is analogous, although here one sees that the net supply of Arrow securities is zero after any history.

The next section shows why a country's current account is a poor measure of the real effects of its fiscal policy. Holding fixed the expected utility of each of the agents in the world economy after any history, a country always has a fiscal policy that satisfies any given constraints on its current account and government deficit. Since such an equilibrium supports arbitrary transfers of resources between countries and between generations, the conventional measure of the current account does not capture the real effects of governments' policies.

\section{WHY THE CONVENTIONAL CURRENT ACCOUNT IS A POOR MEASURE OF THE EXTERNAL DEFICIT}

Until now, I have been very general about the specification of each country's policy of lump-sum tax transfers. Assume now that only country $j$ can levy taxes or subsidies using asset $j$; indeed, it is difficult to imagine another definition of a country in a model this general. Assume also that $G^{j} \cap G_{t} \neq \varnothing$ for each $t \geq 0$; in other words, each country has at least one person born in each period. Again, it would be hard to imagine a country whose population died off and then started up again.

The present-value of country j's conventional current account is ${ }^{12}$

$$
\begin{aligned}
b^{t, j}\left(s^{t}\right) \equiv p^{t} & \cdot\left[\sum_{h \in G^{j}}\left(\omega_{h}^{t}-x_{h}^{t}\right)\right] \\
& +\left[\sum_{k \neq j} q^{0, k} \sum_{h \in G^{j}} m_{h}^{t, k}\right]-\left[q^{0, j} \sum_{h \in G \backslash G^{j}} m_{h}^{t, j}\right] .
\end{aligned}
$$

Equation (3) is a description of the conventional current account because the first term in square brackets allows agents to have endowments located anywhere in the world. If $h \in G^{j}$ owns commodity $(t, i)$ located abroad, then $p^{t, i}\left(s^{t}\right) \omega_{h}^{t, i}\left(s^{t}\right)$ is the present-value of the flow of earnings accruing to ownership of that foreign real asset. The conventional current account consists of three elements. The first is the balance on goods and services, the second is net factor payments, and the third is net transfers from abroad. Since this model is general enough to allow for the domestic ownership of goods located abroad, the first term in brackets in (3) captures both the balance on goods and services and the analog of net factor payments from abroad. The last two terms in brackets in (3) are the present value of

\footnotetext{
${ }^{12}$ For notational convenience, I have suppressed in (3) the dependence of prices and quantities on the history $s^{t}$.
} 
net transfers from abroad, and they are subject to the same ambiguity as annual tax collections in the domestic economy. ${ }^{13}$

The profile of the present value of the current account of country $j$ is

$$
b^{j}=\left(b^{1, j}\left(s^{1}\right), b^{2, j}\left(s^{2}\right), \ldots\right) .
$$

A history-dependent constraint on country j's current account is

$$
\beta^{j}=\left(\beta^{1, j}\left(s^{1}\right), \beta^{2, j}\left(s^{2}\right), \ldots\right),
$$

where $b^{j}=\beta^{j}$ (i.e., $b^{t, j}\left(s^{t}\right)=\beta^{t, j}\left(s^{t}\right)$ for any $\left.s^{t}\right)$. This general formulation allows many specific interpretations. It can express the constraint that country $j$ 's current account is balanced in every period, that the present value of the current account be balanced after every business cycle, or that the asymptotic present value of country $j$ 's net foreign assets be zero. A constraint on a country's current account might be imposed, for example, by an international lending institution.

I will denote currency-j transfers to $h \in G_{t}$ by the sequence

$$
m_{h}^{j}=\left(0, \ldots, 0, m_{h}^{t, j}\left(s^{t}\right), m_{h}^{t+1, j}\left(s_{t+1}\right), 0, \ldots\right) .
$$

Then a fiscal policy for country $j$ is the list

$$
m^{j}=\left\{m_{h}^{j}\right\}_{h \in G}
$$

where the definition of $m_{h}^{j}$ makes explicit that one's transfers depend upon the history of the world economy up until his dotage. Although there is no role for purchasing public goods or imposing distorting taxes in this economy, this limitation is not serious because a country's fiscal policy is really the pattern of financing its public expenditures. Hence a description of how a country's taxes fall on each of the individuals in the world economy is the fullest possible specification of its fiscal policy.

I can now state my result.

${ }^{13}$ A large part of unilateral transfers consist of grants to other foreign governments. During the last two decades, the United States' net transfer payments to foreign governments have been roughly four times as large as net transfer payments to foreign individuals. This poses a technical problem in a model of overlapping generations since one keeps track of transfers from governments to economic agents. This difficulty is overcome by including finitely-lived "administrations" in the list of agents in the world economy. These administrations have no endowments, and their utility functions are constant on the space of commodity bundles. Hence, they have no effect on the material balances condition describing equilibrium. Then the two theorems proved below have the added interpretation that countries can implement their fiscal policies so that the present value of their transfers to foreign administrations remain unchanged when the current account satisfies an arbitrary profile. 
THEOREM. Consider a rational expectations equilibrium consistent with some array of fiscal policies. Let $\beta^{j}$ be a constraint on country j's current account. If currency $j$ is valued after any history, then country $j$ has a fiscal policy satisfying this constraint, and this policy has no effect on the utility of any agent in the world economy after any history.

Proof. See the Appendix.

The proof of the theorem constructs a fiscal policy that works in a simple way. After any history $s^{1}$, the government of country $j$ picks some foreigner in generation 1 and delays transfers (or borrows from abroad in the first period). It promises him sufficiently large future transfers (with state-contingent interest) so that his consumption plans are unchanged for any realization of $s_{2}$. Hence, prices and quantities are unchanged after any history $s^{1}$ and for any realization $s_{2} \cdot{ }^{14}$ The government of country $j$ uses a clever swap of liabilities and assets towards foreigners that has no real effect on any agent and makes the current account as "healthy" as necessary. Then it repeats this process with a new foreigner in the next period. The proof uses the assumption that currency $j$ be valued after any history. But this is the least that one can hope for if an international agency is going to impose an arbitrary state-contingent profile on the current account.

Inspection of equation (3) shows that transfers from country $j$ to its own residents do not affect the current account if the goods and services balance is unchanged. Hence, the government of country $j$ even has a policy tool left over to satisfy any constraint on its own budget deficit: it can time transfers to its own residents in order to satisfy any constraint on its internal deficit! In other words, all of Auerbach and Kotlikoff's (1987) profound objections to the conventional measure of the government budget deficit are still true in the open economy. In fact, only transfers that increase the wealth of generations currently alive can cause a deficit on the balance on goods and services. Hence generational deficits, not conventional deficits, influence the trade account, and there is no simple relationship between a country's generational deficits and its conventional current account because different agents have different marginal propensities to consume from increases in permanent income. ${ }^{15}$

Since a perfect foresight equilibrium is a special case of a rational expectations equilibrium, the theorem is an important generalization of the results of Auerbach and Kotlikoff (1987) and Kelly (1991). These authors had the right intuition: conventional macroeconomic statistics that include transfers among agents have no immediate foundation in utility theory. This conclusion is quite robust, and economists should be cautious about how we interpret some conventional macroeconomic statistics.

It is important to make clear what the theorem does and does not say. A rational expectations equilibrium describes implicitly the utility of each agent in the world

\footnotetext{
${ }^{14}$ Such a policy is akin to Chamley and Polemarchakis' (1984) notion of an open-market operation using a "real" asset.

${ }^{15}$ Many econometric analyses have found only weak evidence that budget deficits affect the conventional current account. See Evans (1990) for a good discussion.
} 
economy after any history. Consider this description as fixed. Then the theorem states that country $j$ has a fiscal policy satisfying any constraint on its external balances, and this policy still supports these utilities. The theorem does not state the selection of a particular equilibrium is independent of what country $j$ does. If agents use information about the timing of a country's deficit as a way of selecting equilibria, then that deficit does matter. In other words, constraints on the current account need not matter, but they may not be entirely irrelevant either.

The conventional measure of the current account is relevant to the extent that people condition their choices on it. If people think a large conventional deficit indicates that country $j$ is undergoing a balance-of-payments crisis, then their actions may well influence the equilibrium in the world economy. But the theorem states that country $j$ always has a fiscal policy that will allow it to run a balanced conventional current account even when agents presume that there is a putative crisis on the external accounts.

Another implication of the theorem is that two identical conventional current accounts may have quite different real economic effects. ${ }^{16}$ Unilateral transfers to abroad have different real economic effects, depending upon the marginal propensities to consume and import of the foreigners receiving the transfers. International economists have long had the intuition that external deficits used to finance domestic investment are somehow different from those that are used to increase domestic consumption. This intuition is quite correct, and I will come back to it in the next section.

\section{A MEANINGFUL MEASURE OF THE EXTERNAL DEFICIT}

The theorem shows that the conventional current account is just not a meaningful measure of a country's external deficit. What is a good measure of this deficit? I propose a measure called the aggregate generational current account. Decreases in the aggregate generational current account indicate that some domestic agent will experience decreased utility after some history. This is a sound utility-theoretic foundation for a proper measure of the external deficit.

Defining the aggregate generational current account will require a bit more notation. Let $I_{h}^{j}$ be the index set of goods in the endowment of agent $h$ that are located in country $j$, and define the sequence

$$
\tilde{\omega}_{h}^{j}= \begin{cases}0 & \text { if }(t, i) \notin I_{h}^{j} \\ \omega_{h}^{t, i} & \text { otherwise. }\end{cases}
$$

The present value of the foreign assets of $h \in G_{t} \cap G^{j}$ are

$$
f_{h}^{j}\left(s^{t}, s_{t+1}\right)=p \cdot\left(\omega_{h}-\tilde{\omega}_{h}^{j}\right)+q \cdot\left(m_{h}-m_{h}^{j}\right),
$$

\footnotetext{
${ }^{16}$ An anonymous referee helped me emphasize this point.
} 
where I have been careful to include both real assets and transfers from foreign governments in this definition. The present value at time $t$ of the expectation of all current and future net foreign assets of country $j$ is

$$
F^{t, j}\left(s^{t}\right)=E\left\{\sum_{k=t-1}^{\infty} \sum_{h \in G_{k} \cap G^{j}} f_{h}\left(s^{k}, s_{k+1}\right)-\sum_{k=t-1}^{\infty} \sum_{h \in G_{k} \backslash G^{j}}\left[p \cdot \tilde{\omega}_{h}^{j}+q \cdot m_{h}^{j}\right]\right\},
$$

where the expectation is taken after history $s^{t} .{ }^{17}$ This expression summarizes the expected value of both real and financial foreign assets. The first term in the brackets represents current and future transfers from abroad to the residents of country $j$, and the second term in the brackets is the expected present value of transfer from country $j$ to abroad. The aggregate generational current account at time $t$ is

$$
\hat{b}^{t, j}\left(s^{t}\right)=F^{t, j}\left(s^{t}\right)-F^{t-1, j}\left(s^{t-1}\right),
$$

where the first implicit expectation is taken after history $s^{t}$ and the second is taken after $s^{t-1}$. This measure capture the annual change in the expected present value of a country's net foreign assets broadly defined.

Fisher and Woo (1994) have constructed an aggregate generational current account using data from the post-war Korean economy. Calculating its historical values entails two big steps. First, one measures current net foreign assets in each year at market value. Second, for each year, one makes a projection of the present value of all net transfers from abroad, based upon information that was known at that time. ${ }^{18}$ Then one sums the present values derived in these two steps and takes first differences. Calculating forecasts of the aggregate generational current account entails making explicit assumptions about exchange rates, interest rates, the market value of net foreign assets, and expected net transfers from abroad.

The aggregate generational current account given in (4) has many appealing properties. First, temporary changes in exchange rates, the market value of net foreign assets, or interest rates have only a minor effect on this measure. On the other hand, a permanent depreciation causes an immediate improvement in the aggregate generational current account. Just as the inflation tax decreases the real liabilities of the central government, so does a depreciation make net transfers to abroad less onerous. Hence, a permanent depreciation increases the utility of some domestic resident. ${ }^{19}$

\footnotetext{
${ }^{17}$ Note that $f_{h}\left(s^{t-1}, s_{t}\right)=f_{h}\left(s^{t}\right)$ for $h \in G_{t-1}$.

${ }^{18}$ For a country with large foreign military commitments, this projection ought to be based on all publicly available information about future foreign policy; for a country with a sizable fraction of its labor force employed abroad, this projection should include the demographics of the work force and its expected future remittances from abroad.

${ }^{19}$ This aspect of the aggregate generational current account implies that much of the literature in international economics on the $J$-curve arises because the external deficit is measured inappropriately.
} 
Also, a permanent increase in the market value of a country's net foreign assets increases its aggregate generational current account, and current and future generations can anticipate higher utility arising from a greater stream of payments from abroad. Further, a permanent increase in real interest rates improves the aggregate generational current account of a debtor country since it lowers the present value of expected payments to abroad. Finally, re-scheduling sovereign debt, so characteristic of the developing country "debt crisis" in the last decade, has no effect on the aggregate generational current account unless it affects the expected stream of payments between countries. ${ }^{20}$

The aggregate generational current account also allows one to differentiate between external deficits arising from consumption binges and those arising from increases in permanent income. Think of a country that has experienced an increase in expected net foreign assets, perhaps owing to a technological discovery making all of its generations better off. Such a country might quite naturally import in anticipation of higher future income. This activity appears as a deficit on the conventional current account, whereas the aggregate generational current account would quite rightly show a surplus. On the other hand, a country whose government runs generational deficits that are financed by foreigners must consider not only the conventional current account deficit but also the present value of expected payments to abroad. Of course, the aggregate generational current account captures these expected payments.

\section{CONCLUSION}

I have made a theoretical point in this paper: the conventional measure of the current account is not an economically meaningful concept. This fact is true for growing economies and for equilibria that do not satisfy an inter-temporal efficiency criterion. ${ }^{21}$ Indeed, it is a robust property of equilibrium in dynamic models. This result has been well known for the budget deficit in the closed economy, and it has spurred some important research on appropriate measures of fiscal policy. This line of research has important implications for the open economy, and it casts doubts on whether the current definitions of "structural adjustments" make sense.

The aggregate generational current account is easier to construct than Auerbach, Gokhale, and Kotlikoff's generational accounts because one need not keep track of

\footnotetext{
${ }^{20}$ There is little evidence that re-scheduling changed the market value of the North American banks who held much of this debt; see Musumeci and Sinkey (1990) for an event study. After having defined the aggregate generational current account, I am inclined to believe that the developing country "debt crisis" in the 1980 's was much ado about nothing. Still, in the last decade, the United States government developed an inter-agency task force to assess the repayment capabilities of the major sovereign debtors, and the Bank of International Settlements created an "early warning system" to keep track of the aggregate exposure of commercial banks in the major industrial countries to sovereign debt. Both these institutions are apposite if expected payments from abroad are what matters in measuring a country's external accounts.

${ }^{21}$ Nothing in the arguments above assumed that there was a uniform upper bound on the conventional current account, government deficit, or the present value of endowments. In other words, we never assumed that the "interest rate" was greater than the "growth rate" of any macroeconomic variable.
} 
net official transfers to abroad for each generation. Instead, the nature of external accounts is such that one is interested in the sum across generations of these transfers. But, in another sense, my measure is a challenge to the empirical work on generational accounts. Since this work has been accomplished for the closed economy, it has assumed implicitly that the present value of net transfers from abroad is zero. There is no theoretical justification for this assumption in the model of overlapping generations, and there is little empirical support for it in the long time series on the present values of net foreign assets of several major industrial countries. While recognizing that the empirical work on generational accounts has been extremely valuable to date, I hope that the measure I have proposed will spur further empirical research in this area.

The Ohio State University, U.S.A.

\section{APPENDIX}

Proof of THE THEOREM. Let $m^{j}$ be the fiscal policy of country $j$, and fix all other countries' policies. Let the constraint on the current account of country $j$ be $\beta^{j}$. I will construct a new fiscal policy $\tilde{m}^{j}$ that leaves unchanged the present value of the wealth of every agent in the world economy and satisfies $b^{t, j}\left(s^{t}\right)=\beta^{t, j}\left(s^{t}\right)$ after any history.

First, for any history $s^{1}$, let $\tilde{m}_{h}^{1, j}\left(s^{1}\right)=m_{h}^{1, j}\left(s^{1}\right)$ for each $h \in G_{0}$. Second, for any realization $s_{2}$, let

$$
\left\{\left(\tilde{m}_{h}^{1, j}\left(s^{1}\right), \tilde{m}_{h}^{2, j}\left(s_{2}\right)\right)\right\}_{h \in G_{1}}=\left\{\left(m_{h}^{1, j}\left(s^{1}\right), m_{h}^{2, j}\left(s_{2}\right)\right)\right\}_{h \in G_{1}}
$$

for all but one agent $h_{1} \in G_{1} \cap\left(G \backslash G^{j}\right)$. For this agent, let

$$
\tilde{m}_{h_{1}^{1, j}}^{1, j}\left(s^{1}\right)=\beta^{1, j}\left(s^{1}\right) / q^{1, j}\left(s^{1}\right)-\sum_{h \in\left(G_{0} \cup G_{1}\right) \backslash\left\{h_{1}\right\}} m_{h}^{1, j}\left(s^{1}\right) .
$$

Then choose $\tilde{m}_{h_{1}}^{2, j}\left(s_{2}\right)$ so that

$$
\tilde{m}_{h_{1}}^{2, j}\left(s_{2}\right)=m_{h_{1}}^{2, j}\left(s_{2}\right)-\left[q^{1, j}\left(s^{1}\right) / q^{2, j}\left(s_{2}\right)\right] \tilde{m}_{h_{1}}^{1, j}\left(s^{1}\right)
$$

where again $m_{h_{1}}^{2, j}\left(s_{2}\right)$ is given by the policy $m^{j}$. Note that I have not changed the present value of the wealth of any agent $h \in G_{0} \cup G_{1}$ after any history $s^{2}$.

Let $P_{\lambda}$ be the distribution induced by $\lambda$ on the product space $\prod_{t=1}^{\infty} S_{t}$. Since $\lambda$ is the unique invariant measure, this new fiscal policy does not affect $P_{\lambda}$. Hence, asset demands and allocations satisfy the equilibrium conditions (2) for the case where $t=1$. Thus the first term on the right side of (3) is unchanged, and $b^{1, j}\left(s^{1}\right)=\beta^{1, j}\left(s^{1}\right)$.

Assume $\tilde{m}^{j}$ has been constructed for the agents in $G_{0} \cup \cdots \cup G_{t}$. Let

$$
\left\{\left(\tilde{m}_{h}^{t+1, j}\left(s^{t+1}\right), \tilde{m}_{h}^{t+2, j}\left(s_{t+2}\right)\right)\right\}_{h \in G_{t+1}}=\left\{\left(m_{h}^{t+1, j}\left(s^{t+1}\right), m_{h}^{t+2, j}\left(s_{t+2}\right)\right)\right\}_{h \in G_{t+1}}
$$


for all but one agent $h_{t+1} \in G_{t+1} \cap\left(G \backslash G^{j}\right)$. For this agent, let

$$
\tilde{m}_{h_{t+1}}^{t+1, j}\left(s^{t+1}\right)=\beta^{t+1, j}\left(s^{t+1}\right) / q^{t+1, j}\left(s^{t+1}\right)-\sum_{h \in\left(G_{t} \cup G_{t+1}\right) \backslash\left\{h_{t+1}\right\}} m_{h}^{t+1, j}\left(s^{t+1}\right) .
$$

Then choose $\tilde{m}_{h_{t+1}}^{t+2, j}\left(s_{t+2}\right)$ so that

$$
\tilde{m}_{h_{t+1}}^{t+2, j}\left(s_{t+2}\right)=m_{h_{t+1}}^{t+2, j}\left(s_{t+2}\right)-\left[q^{t+1, j}\left(s^{t+1}\right) / q^{t+2, j}\left(s_{t+2}\right)\right] \tilde{m}_{h_{t+1}}^{t+1, j}\left(s^{t+1}\right),
$$

where again $m_{h_{t+1}}^{t+2, j}\left(s_{t+2}\right)$ is given by the policy $m^{j}$. Again, I have not changed the present value of the wealth of any agent $h \in G_{0} \cup \cdots \cup G_{t+1}$ after any history $s^{t+2}, P_{\lambda}$ is unchanged, asset demands satisfy (2), and $b^{t+1, j}\left(s^{t+1}\right)=\beta^{t+1, j}\left(s^{t+1}\right)$ after any history.

The proof then proceeds by induction.

\section{REFERENCES}

Auerbach, A. J., J. Gokhale, and L. J. Kotlikoff, "Generational Accounts: A Meaningful Alternative to Deficit Accounting," in D. Bradford, ed., Tax Policy and the Economy, Vol. 5, (Cambridge: National Bureau of Economic Research and MIT Press, 1991).

— and L. J. Kotlikoff, Dynamic Fiscal Policy (Cambridge: Cambridge University Press, 1987). Balasko, Y., D. Cass, and K. Shell, "Existence of Competitive Equilibrium in a General Overlapping Generations Model," Journal of Economic Theory 23 (1980), 307-322.

- AND K. SHELl, "The Overlapping Generations Model I: The Case of Pure Exchange without Money," Journal of Economic Theory 23 (1980), 280-306.

— AND —- "The Overlapping Generations Model II: The Case of Pure Exchange with Money," Journal of Economic Theory 24 (1981), 112-142.

Chamley, C. And H. Polemarchakis, “Assets, General Equilibrium and the Neutrality of Money," Review of Economic Studies 51 (1984), 129-138.

Dewald, W. G. ANd M. Ulan, "The Twin-Deficit Illusion," Cato Journal 9 (1990), 689-718.

Evans, P., "Do Budget Deficits Affect the Current Account?" mimeo, The Ohio State University, 1990.

FisHer, E. O’N., "Sustainable Balance of Trade Deficits,” Journal of Monetary Economics 25 (1990), 411-430.

- AND Y. S. Woo, "A New Measure of the Korean Current Account," mimeo, The Ohio State University, 1995.

HowARD, D., "Implications of the U.S. Current Account Deficit," Journal of Economic Perspectives 3 (1989), 153-165.

KElly, M. A., “Does Gramm-Rudman Matter?” CAE Working Paper No. 91-19, Cornell University, 1991.

Manuelli, R. E. And J. Peck, "Exchange Rate Volatility in an Equilibrium Asset Pricing Model," International Economic Review 31 (1990), 559-574.

McCandless, G., JR. WiTH N. Wallace, Introduction to Dynamic Macroeconomic Theory (Cambridge: Harvard University Press, 1991).

Musumeci, J. J. AND J. F. Sinkey, "The International Debt Crisis, Investor Contagion, and Bank Security Returns in 1987: The Brazilian Experience," Journal of Money, Credit, and Banking 22 (1990), 209-220.

Williamson, J., ed., IMF Conditionality (Cambridge: MIT Press, 1983). 